\title{
Colposcopic evaluation of cervical erosion in symptomatic women
}

\author{
Pooja Patil $^{1 *}$, Priyanka Sharma ${ }^{2}$
}

\begin{abstract}
${ }^{1}$ Department of Obstetrics and Gynecology, L. N. Medical College, Bhopal, Madhya Pradesh, India
${ }^{2}$ Department of Obstetrics and Gynecology, Sitadevi Hospital, Jaipur, Rajasthan, India
\end{abstract}

Received: 17 April 2017

Accepted: 22 April 2017

\section{*Correspondence:}

Dr. Pooja Patil,

E-mail: pooja_gynec@yahoo.co.in

Copyright: () the author(s), publisher and licensee Medip Academy. This is an open-access article distributed under the terms of the Creative Commons Attribution Non-Commercial License, which permits unrestricted non-commercial use, distribution, and reproduction in any medium, provided the original work is properly cited.

\section{ABSTRACT}

Background: This study was carried out to find the colposcopic findings in the symptomatic patients with cervical erosion and correlate the findings with cytology and histopathology.

Methods: All the patients coming to gynaecological OPD with symptoms of white discharge, pruritus vulvae, menstrual irregularities were examined by per speculum examination and all those who had cervical erosion were included in the study and pap smear and colposcopy both were done in all subjects. The colposcopic guided biopsy was done in women with abnormal findings on colposcopy (50 women) and reports were compared. Abnormal colposcopic findings were graded according to Reid's colposcopic index (RCI).

Results: Majority of patients came with the complaint of white discharge per vaginum (55\%).Out of 120 patients, 85 women $(70.9 \%)$ had inflammatory pap smear and 35 women $(29.1 \%)$ had abnormal pap smear. All patients underwent colposcopic examination and out of 120 patients, 67(55.8\%) showed normal colposcopic findings and 50 women (41.6\%) had abnormal colposcopic finding and biopsy was taken. 3 women had unsatisfactory colposcopy. Histopathology confirmed 24 (48\%) women with CIN I and 12 (24\%) CIN II and 6 (12\%) CIN III and 2 (4\%) women with carcinoma cervix. The colposcopy findings and histopathology correlated in $88 \%$.

Conclusions: Colposcopy should be prescribed to all symptomatic patients with cervical erosion as it is a good diagnostic tool for pre-malignant conditions of cervix and correlates well with histopathological findings.

Keywords: Cervical erosion, Colposcopy, Cytology, Histopathology

\section{INTRODUCTION}

India has a population of 453.02 million women ages 15 years and older who are at risk of developing cervical cancer. Current estimates indicate that every year 122844 women are diagnosed with cervical cancer and 67477 die from the disease. Cervical cancer ranks as the 2nd most frequent cancer among women in India and the 2nd most frequent cancer among women between 15 and 44 years of age. ${ }^{1}$

Cervical erosion/ectropion (or cervical eversion) is a condition in which the central (endocervical) columnar epithelium protrudes out through the external os of the cervix and onto the vaginal portion of the cervix, undergoes squamous metaplasia, and transforms to stratified squamous epithelium. ${ }^{2}$

When symptoms such as postcoital bleeding and troublesome vaginal discharge occur in women in the presence of cervical ectropion, it becomes important to identify promptly whether the ectropion is simply a benign lesion that has associated symptoms or whether it is a significant sign of associated infection, CIN or even cancer.

Although not an abnormality, it is indistinguishable from early cervical cancer; therefore, further diagnostic studies (e.g., Pap smear, biopsy) must be performed for a differential diagnosis. ${ }^{3}$ 
Papanicolaou (Pap) smear cytology has remained an important tool in the screening for cervical cancer. ${ }^{4}$ Ideally, all patients with abnormal Papanicolaou smear cytology results should undergo colposcopic examination. ${ }^{5}$ Thus in our study we have taken both pap smear and colposcopy and wherever required colposcopic guided biopsy in symptomatic patients with cervical erosion and compared the results of all.

\section{METHODS}

This study is a prospective observational study which was carried out at J. K. Hospital, a tertiary care hospital, from January 2014 to December 2016, with prior permission from Institute ethical committee. All patients coming to
Gynec OPD with complaints of white discharge per vaginum, itching in private parts, irregular bleeding, intermenstrual bleeding and post-coital bleeding were subjected to detailed history and gynaecological examination.

\section{Inclusion criteria}

All patients with the above complaints having cervical erosion on per speculum examination.

\section{Exclusion criteria}

Pregnancy, known case of CIN or treated case of CIN or cervical cancer, patients on Oral Contraceptive pills.

Table 1: Modified Reid's colposcopic index (RCI).

\begin{tabular}{|c|c|c|c|}
\hline Colposcopy signs & Zero point & One point & Two point \\
\hline Colour & $\begin{array}{l}\text { Low-intensity acetowhitening (not completely } \\
\text { opaque); indistinct acetowhitening; transparent or } \\
\text { translucent acetowhitening acetowhitening beyond } \\
\text { the margin of the transformation zone pure snow- } \\
\text { white colour with intense surface shine }\end{array}$ & $\begin{array}{l}\text { Intermediate } \\
\text { shade - } \\
\text { grey/white colour } \\
\text { and shiny surface } \\
\text { (most lesions } \\
\text { should be scored } \\
\text { in this category) }\end{array}$ & $\begin{array}{l}\text { Dull, opaque, oyster } \\
\text { white; grey }\end{array}$ \\
\hline $\begin{array}{l}\text { Lesion margin } \\
\text { and } \\
\text { Surface } \\
\text { configuration }\end{array}$ & $\begin{array}{l}\text { Microcondylomatous or micropapillary contour flat } \\
\text { lesions with indistinct margins feathered or finely } \\
\text { scalloped margins angular, jagged lesions. Satellite } \\
\text { lesions beyond the margin of the transformation } \\
\text { zone } e^{1,3}\end{array}$ & $\begin{array}{l}\text { Regular-shaped, } \\
\text { symmetrical } \\
\text { lesions with } \\
\text { smooth, straight } \\
\text { outlines }\end{array}$ & $\begin{array}{l}\text { Rolled, peeling edges } \\
\text { Internal demarcations } \\
\text { between areas of } \\
\text { differing colposcopic } \\
\text { appearance- a central } \\
\text { area of high-grade } \\
\text { change and peripheral } \\
\text { area of low-grade } \\
\text { change }^{2}\end{array}$ \\
\hline Vessels & $\begin{array}{l}\text { Fine/uniform-calibre vessels closely and uniformly } \\
\text { placed Poorly formed patterns of fine punctation } \\
\text { and/or mosaic vessels beyond the margin of the } \\
\text { transformation zone Fine vessels within } \\
\text { microcondylomatous or micropapillary lesions }{ }^{4,6}\end{array}$ & Absent vessels & $\begin{array}{l}\text { Well defined coarse } \\
\text { punctuation or mosaic, } \\
\text { sharply demarcated } \\
\text { - and randomly and } \\
\text { widely placed }\end{array}$ \\
\hline Iodine staining & $\begin{array}{l}\text { Positive iodine uptake giving mahogany-brown color } \\
\text { negative uptake of insignificant lesion, i.e., yellow } \\
\text { staining by a lesion scoring three points or less on the } \\
\text { first three criteria areas beyond the margin of the } \\
\text { transformation zone, conspicuous on colposcopy, } \\
\text { evident as iodine-negative areas (such areas are } \\
\text { frequently due to parakeratosis) }\end{array}$ & $\begin{array}{l}\text { Partial iodine } \\
\text { uptake - } \\
\text { variegated, } \\
\text { speckled } \\
\text { appearance }\end{array}$ & $\begin{array}{l}\text { Negative iodine uptake } \\
\text { of significant lesion, } \\
\text { i.e., yellow staining by } \\
\text { a lesion already scoring } \\
\text { four points or more on } \\
\text { the first three criteria }\end{array}$ \\
\hline
\end{tabular}

Demographic data of the patient like age, age of the patient at marriage and parity of the patient were noted. Women in which cervical erosion was present on per speculum examination, a pap smear was taken and simultaneously colposcopy was done, if no cervicovaginal infections were present. Beforehand consent was taken from the patient for the procedure. Women who had cervico-vaginal infections were given antibiotic course of 7 days and called after that for colposcopy with the pap smear report. 3\% aceticacid and 50\% Lugol's iodine was used to identify the suspicious areas on colposcopy.

- Microexophytic surface contour indicative of colposcopically overt cancer is not included in this scheme 
- Epithelial edges tend to detach from underlying stroma and curl back on themselves. Note: Prominent low-grade lesions often are overinterpreted, while subtle avascular patches of HSIL can easily be overlooked

- Score zero even if part of the peripheral margin does have a straight course

- At times, mosaic patterns containing central vessels are characteristic of low-grade histological abnormalities. These low-grade-lesion capillary patterns can be quite pronounced. Until the physician can differentiate fine vascular patterns from coarse, overdiagnosis is the rule

- Branching atypical vessels indicative of colposcopically overt cancer are not included in this scheme

- Generally, the more microcondylomatous the lesion, the lower the score. However, cancer also can present as a condyloma, although this is a rare occurrence

- Parakeratosis: a superficial zone of cornified cells with retained nuclei.

Abnormal colposcopic findings were graded according to Reid's index. The Reid's colposcopic index (RCI) considers four colposcopic signs, which are: Margin or border of lesion, Colour of lesion following application of 5\% acetic acid solution, blood vessel characteristics within the lesion and response of the lesion to the application of Lugol's iodine solution.

Each colposcopic sign is subdivided into three categories. Each category is assigned a numerical value from 0 to 2 . Each of the four colposcopic signs is considered separately, and numerical scores are assigned respectively, depending on the severity of that characteristic within the detected cervical lesion (Table 1 and 2).

Table 2: Colposcopic prediction of histologic diagnosis using the Reid colposcopic index (RCI).

\begin{tabular}{|ll|}
\hline RCI (overall score) & Histology \\
\hline $0-2$ & Likely to be CIN 1 \\
$3-4$ & $\begin{array}{l}\text { Overlapping lesion: likely to } \\
\text { be CIN 1 or CIN 2 }\end{array}$ \\
\hline $5-8$ & Likely to be CIN 2-3 \\
\hline
\end{tabular}

Punch biopsies were taken wherever required. The biopsy was fixed in $10 \%$ formalin and sent for histopathological examination. Women were advised to follow up after 7 days with HPE report and the treatment was given according to the report.

Data was collected and recorded in numbers and percentages. The results of pap smear, colposcopic findings, colposcopic guided biopsies were correlated. Accuracy of colposcopic examination was calculated by standard statistical methods.

\section{RESULTS}

In our study $23 \%$ of patients who were examined were in the 20-30-year age group and majority (39.2\%)were in 31-40 years of age group (Table 3 ).

Table 3: Age of patient $(n=120)$.

\begin{tabular}{|lll|}
\hline Age & No. & $\%$ \\
\hline $20-30$ & 28 & $23.3 \%$ \\
\hline $31-40$ & 47 & $39.2 \%$ \\
\hline $41-50$ & 33 & $27.5 \%$ \\
\hline $51-60$ & 12 & $10 \%$ \\
\hline
\end{tabular}

$70 \%$ women got married at 15-20 years of age and thus their sexual life started early which is one of the predisposing factor of cervical carcinoma (Table 4).

Table 4: Age at marriage.

\begin{tabular}{|lll|}
\hline Age & No. & $\%$ \\
\hline $15-20$ years & 84 & 70 \\
\hline $21-30$ years & 36 & 30 \\
\hline
\end{tabular}

$76 \%$ women were multiparous (Table 5). Majority of patients came with the complaint of white discharge per vaginum (55\%) and others with complaint of problems in menstruation $(28.3 \%$ ) like irregular cycles, menorrhagia or intermenstrual bleeding. Approximately $12 \%$ patients had complaint of itching in private parts and only $5 \%$ patients had complaint of post coital bleeding (Table 6).

Table 5: Parity.

\begin{tabular}{|lll|}
\hline Parity & No. & $\%$ \\
\hline Nullipara & 10 & 8.3 \\
\hline Multipara (1-4) & 92 & 76.7 \\
\hline Grand multipara (>=5) & 18 & 15 \\
\hline
\end{tabular}

Table 6: Clinical presentation.

\begin{tabular}{|lll|}
\hline Symptom & No. & $\%$ \\
\hline Discharge per vaginum & 66 & $55 \%$ \\
\hline Pruritus vulvae & 14 & $11.7 \%$ \\
\hline Abnormal menstruation & 34 & $28.3 \%$ \\
\hline Post coital bleeding & 6 & $5 \%$ \\
\hline
\end{tabular}

Out of 120,85 women $(70.9 \%)$ had inflammatory pap smear and 35 women $(29.1 \%$ ) had abnormal pap smear. In $35(29 \%)$ abnormal pap smear, $24(20 \%)$ reported as LSIL (CIN I) and 6 patients (5\%) reported as HSIL (CIN II and CIN III). 2 patients reported as ASCUS and 2 as AGUS. The patients with AGUS were further investigated by endocervical and endometrial biopsy. 2 patients were reported as case of carcinoma cervix (Table 7). All patients underwent colposcopic examination and out of 120 patients, $67(55.8 \%)$ showed normal colposcopic findings. 50 women $(41.6 \%)$ had abnormal 
colposcopy findings which was graded according to Reid's index. 3 women had unsatisfactory colposcopy.

Table 7: Pap smear report.

\begin{tabular}{|lll|}
\hline Pap smear & No. & $\%$ \\
\hline Inflammatory & 85 & 70.9 \\
\hline LSIL & 24 & 20 \\
\hline HSIL & 6 & 5 \\
\hline ASCUS & 2 & 1.7 \\
\hline AGUS & 1 & 0.8 \\
\hline Carcinoma cervix & 2 & 1.7 \\
\hline
\end{tabular}

Thus, pap smear diagnosed abnormality in 35 women $(29.1 \%)$ women whereas colposcopy diagnosed the abnormalities in 50 (41.6\%) women. On colposcopy, 25 patients had the score of 0-2, which corresponded with CIN I.15 patients had the score of 3-4, which corresponded with CIN I to CIN II.10 patients scored 5-8 in which two cases were suspected carcinomas (Table 8).

Table 8: Colposcopy findings $(n=120)$ according to Reid's index.

\begin{tabular}{|lll|}
\hline Colposcopy finding & No. & $\%$ \\
\hline Normal & 67 & 55.8 \\
\hline Unsatisfactory & 3 & 2.5 \\
\hline $0-2$ score & 25 & 20.9 \\
\hline $3-4$ score & 15 & 12.5 \\
\hline $5-8$ score & 10 & 8.3 \\
\hline Total & $\mathbf{1 2 0}$ & $\mathbf{1 0 0}$ \\
\hline
\end{tabular}

Biopsies were taken from all patients with abnormal colposcopic findings and histopathology reports collected. Out of 50 patients, histopathology diagnosed $24(48 \%)$ women with CIN I and 12 (24\%) CIN II and 6 (12\%) CIN III. 2 cases confirmed as carcinoma cervix (Table 9).

Table 9: Biopsy findings $(n=50)$.

\begin{tabular}{|lll|}
\hline Biopsy findings & No. & $\%$ \\
\hline Chronic cervicitis & 6 & $12 \%$ \\
\hline CIN-I & 24 & $48 \%$ \\
\hline CIN-II & 12 & $24 \%$ \\
\hline CIN-III & 6 & $12 \%$ \\
\hline Carcinoma cervix & 2 & $4 \%$ \\
\hline
\end{tabular}

The colposcopy findings and histopathology reports were co-relating as can be seen in Table 10 .

On comparing, 25 women with colposcopy score of 0-2, histopathology reported as chronic cervicitis in 5 and CIN $\mathrm{I}$ in 20 women.

15 women with colposcopy score 3-4 were reported as chronic cervicitis in 1 , CIN I in 4 and CIN II in 10 on histopathology.
Out of 10 women with score 5-8 on colposcopy,2 turned out to be CIN II, 6 cases as CIN III and 2 cases as carcinoma cervix. Thus, the correlation between colposcopy and histopathology was $88 \%$.

\section{Table 10: Correlation of colposcopy findings and histopathology report.}

\begin{tabular}{|ll|}
\hline $\begin{array}{l}\text { Colposcopy finding } \\
\text { Normal }(n=67)\end{array}$ & Biopsy findings \\
Unsatisfactory $(n=3)$ & Not taken \\
Score $0-2(n=25)$ & $\begin{array}{l}\text { Chronic cervicitis }(n=5) \\
\text { CIN I }(n=20)\end{array}$ \\
\hline Score 3-5 $(n=15)$ & $\begin{array}{l}\text { Chronic cervicitis }(n=1) \\
\text { CIN I }(n=4) \\
\text { CIN II }(n=10)\end{array}$ \\
Score 6-8 $(n=10)$ & CIN II $(n=2)$ \\
& CIN III $(n=6)$ \\
& Carcinoma cervix $(n=2)$ \\
\hline
\end{tabular}

CIN I patients were advised for cryosurgery or for regular follow up. CIN II and CIN III patients were advised either the conservative treatment as cryosurgery or extensive surgery as hysterectomy depending on their age and completion of family.

Patients diagnosed with chronic cervicitis were given the course of antibiotics. 2 patients diagnosed as carcinoma cervix which were also diagnosed on pap smear and colposcopy, were staged and treated accordingly.

\section{DISCUSSION}

Routine cervical cytology has been shown to be an effective screening tool for CIN and cervical cancer. However, negative cytology does not always rule out CIN. 6,7 As also found in our study that pap smear diagnosed abnormality in 35 women $(29.1 \%)$ women whereas colposcopy diagnosed the abnormalities in 50 $(41.6 \%)$ women and therefore these 15 women (11.6\%) would have missed if colposcopy was not done simultaneously. Referral for colposcopy, where the cervix may be closely inspected and biopsied, may still reveal CIN in some, even if a recent smear result is negative. ${ }^{7}$

In a study by Gupta V et al, colposcopy was done following cytological examination in 177 (59\%) patients. The findings correlated in $160(90.39 \%)$ patients and did not correlate in $15(8.47 \%)$ patients. ${ }^{8}$ Colposcopy was unsatisfactory in 2 of these patients.

In present study, we did colposcopy in all patients $(n=120)$ along with cytological examination and the findings co-related in 102 patients $(85 \%)$ and did not correlate in 15 patients $(12.5 \%)$ which is comparable to the study by Gupta V et al.

In a study by Kumari $\mathrm{M}$ et al on colposcopy in cervical erosion patients, $68 \%$ revealed normal findings and $30 \%$ revealed abnormalities like acetowhite areas, abnormal 
vascular patterns, mosaic and punctations and iodine negative areas. ${ }^{9}$ In the study by Bangal VB et al out of 100 patients of cervical erosion, $67 \%$ had normal colposcopic findings and $30 \%$ had abnormal findings. ${ }^{10}$ Jyothi et al in their study of 200 high risk patients in the age group of 35 to 60 years reported abnormal colposcopy in $65 \%$ cases. $^{11}$

In present study $55.8 \%$ revealed normal findings and $41.6 \%$ revealed abnormal findings on colposcopy which is more than the above-mentioned studies as we used Reid's colposcopic index (RCI) for colposcopy findings and they used coppleson's grading system. Thus, Reid's colposcopic index reveals more abnormal cases on colposcopy than Coppleson's grading system. Gupta V et al did colposcopy in 300 patients and colposcopic guided biopsy was obtained in $104(34.66 \%)$ patients. $^{8}$ In 2 of these patients, colposcopy was unsatisfactory. In Meenakshi et al study, 15 cases who had abnormal colposcopy findings were subjected to colposcopy guided biopsy. ${ }^{9}$ In present study, out of 120 patients who underwent colposcopy, colposcopic guided biopsy was obtained in 50 women $(41.6 \%)$.

In present study, colposcopy predicted 25 women in CIN I (20.9\%), 15 women in CIN II (12.5\%) and 10 women in CIN III (8.3\%) which included 2 suspected carcinomas also. Histopathology confirmed CIN I in 24 women, CIN II in 12 and CIN III in 6 women. Carcinoma cervix was confirmed in 2 women. 6 cases turned out to be chronic cervicitis. Thus, the co-relation between colposcopy findings and histopathology was $88 \%$ in this study.

In the study by Ramesh et al on colposcopic evaluation of unhealthy cervix, the accuracy of the colposcopic directed biopsies was $83 \%$ which is comparable with our study. ${ }^{12}$ In the study by Gupta et al also correlation between colposcopic findings and HPE results was seen in $90(88.23 \%)$ patients which is also comparable with our study. ${ }^{8}$ Meenakshi et al found $96 \%$ correlation between colposcopy and histology. ${ }^{9}$

Since the cancer cercix has long duration of premalignant conditions in which it can be diagnosed and treated, colposcopy should be the screening test of choice in the patients with cervical erosion. Massad et al concluded that until better strategies are developed in order to find CIN2+ in women with borderline changes, the biopsies of all the acetowhite lesions will yield the greatest sensitivity for detecting cervical precancer. ${ }^{13}$

\section{CONCLUSION}

Cervical erosion is a very common finding on per speculum examination. It can be the outcome of infection or pre-neoplastic conditions. From our study, we conclude that all women with symptoms and presence of cervical erosions on examination should undergo colposcopic examination and guided biopsies to detect more number of cases in premalignant state and early cervical cancers. There is good correlation between colposcopy and histopathology and both are complimentary to each other.

Funding: No funding sources

Conflict of interest: None declared

Ethical approval: The study was approved by the Institutional Ethics Committee

\section{REFERENCES}

1. WHO/ICO; Information centre on HPV and cervical cancer. India human papillomavirus and related cancers, fact sheet; 2016. Available at http://www.hpvcentre.net/statistics/reports/IND_FS.pdf. Accessed on 15 December 2016.

2. Katz: Comprehensive Gynecology, 5th Edition Mosby's Guide to Physical Examination, 7th Edition; 2012:558.

3. Ugboma HAA, Aburoma HLS. Pap smear: an important screening technique for preventing and detecting cervical cancer. Cont J Med Res. 2010;4:13-7.

4. Shafi MI. Premalignant and malignant lesions of the cervix. In: Edmonds DK, editor. Dewhurst's Textbook of Obstetrics and Gynaecology. 7th ed. Oxford, UK: Blackwell Publishing; 2007.

5. Souter P. A practical guide to colposcopy. Oxford: Oxford University Press; 1993.

6. Kesic V, Soutter WP, Jusnic N. A comparison of cytology and cervicography in cervical screening. Int $\mathbf{J}$ Gynecol Cancer. 1993;3:395-8.

7. Gupta V, Tandon A, Nanda A, Sharma A, Bansal N. Colposcopic evaluation of cervical lesions: a prospective study. Int J Clin Trials. 2014;1:110-3.

8. Kumari M, Murari K, Kumari M. Role of colposcopy in management of cervical erosion in rural population of Eastern Bihar. Inter J Cur Res. 2016;8(11):41268-70.

9. Bangal VB, Patil NA, Gavhane SP, Shinde KK, Colposcopy guided management of cervical erosions in rural population. Sch J App Med Sci. 2014;2(1C):2615 .

10. Jyoti R, Gupta P, Rao R, Sood PL, Parasher N. Correlation between colposcopy, cytology, and histopathology in high risk patients for cervical cancer in perimenopausal women in Himachal Pradesh, India. J South Asian Federat Menop Soc. 2013;1(1):21-3.

11. Ramesh G, Sudha R, Jayashree AK, Padmini J. Colposcopic evaluation of the unhealthy cervix. J Clin Diagnost Res. 2012;6(6):1026-28.

12. Massad LS, Jeronimo J, Katki HA, Schiffman M. The accuracy of the colposcopic grading for the detection of high-grade cervical intraepithelial neoplasia. J Low Genit Tract Dis. 2009;13(3):137-44.

Cite this article as: Patil P, Sharma P. Colposcopic evaluation of cervical erosion in symptomatic women. Int J Reprod Contracept Obstet Gynecol 2017;6:2207-11. 